\title{
Comparison of Intestinal Stent Placement Followed By Laparoscopic Surgery and Emergency Surgery in Obstructive Colorectal Cancer: A Retrospective Analysis and Meta-analysis
}

\section{Zhengwei Li}

First Peoples Hospital of Shunde: Shunde Hospital of Southern Medical University Yan Lu

First Peoples Hospital of Shunde: Shunde Hospital of Southern Medical University

\section{Kang Wang}

First Peoples Hospital of Shunde: Shunde Hospital of Southern Medical University

Tianyou Liao

First Peoples Hospital of Shunde: Shunde Hospital of Southern Medical University

\section{Yongle Ju}

First Peoples Hospital of Shunde: Shunde Hospital of Southern Medical University

\section{Yuanhong Peng}

First Peoples Hospital of Shunde: Shunde Hospital of Southern Medical University

Manzhao Ouyang ( $\sim$ doctorken@smu.edu.cn)

First Peoples Hospital of Shunde: Shunde Hospital of Southern Medical University

\section{Research Article}

Keywords: intestinal stent, laparoscopy, anastomotic leakage, colorectal cancer, intestinal obstruction

Posted Date: January 12th, 2022

DOI: https://doi.org/10.21203/rs.3.rs-965424/v1

License: (c) (i) This work is licensed under a Creative Commons Attribution 4.0 International License. Read Full License 


\section{Abstract}

Background: For patients with colorectal cancer and malignant intestinal obstruction, it is still controversial to perform endoscopic intestinal stent placement followed by laparoscopic surgery. This study compares the endoscopic intestinal stent placement followed by laparoscopic surgery and emergency surgery in patients with colorectal cancer and malignant intestinal obstruction.

Method: 11 compliant publications from Pubmed, Cochrane and Embase databases were analyzed using Revies Manager 5.2 software. SPSS 21 was used to retrospectively analyze 99 patients admitted to our center from 2014 to 2019.

Results: There were significant differences between the two groups in three of the five criteria. In the SBTS group, the perioperative mortality rate was lower, with an OR of 0.46 ( $95 \% \mathrm{Cl}: 0.22-0.95, \mathrm{P}=0.04)$, the incidence of postoperative wound infection was lower; OR was 0.44 (95\% Cl: 0.24-0.82, $\mathrm{P}=0.009)$; Postoperative hospital stay was shorter, MD was -2.07 (95\% Cl: $-2.55-1.59, \mathrm{P}<0.00001$ ).

Retrospective analysis of the clinical outcome differences between the SBTS group and ES group in our center: Compared to the ES group, the SBTS group displayed lower infection rate of surgical incision $\left.\left(X^{2}=3.94, P=0.04\right)\right)$; no difference in the frequency of occurrence of anastomotic leakage $\left(X^{2}=0.18, P=0.67\right)$, did not reduce perioperative mortality $\left(X^{2}=0.94, P=0.33\right)$; shorter operating time $(204.13 \pm 37.35 \mathrm{~min})$ $(\mathrm{t}=5.08, \mathrm{P}=0.000)$, lower intraoperative blood loss $(155.65 \pm 94.90 \mathrm{ml})(\mathrm{t}=3.90, \mathrm{P}=0.001)$; and shorter postoperative hospital stay $(12.91 \pm 5.47 \mathrm{~d})(\mathrm{t}=2.64, \mathrm{P}=0.01)$.

Conclusion: Compared the emergency surgery group, endoscopic intestinal stent placement followed by the laparoscopic surgery can reduce perioperative mortality, postoperative wound infection, intraoperative blood loss, and the length of postoperative hospital stay. There was no difference between the two methods as far as the incidence of posterior anastomotic leakage and operating time were concerned.

\section{Introduction}

Cancer is a common malignant tumor of the gastrointestinal system. The first symptom in 7 to $28 \%$ of the patients is complete or partial intestinal obstruction [1]. These patients often need to undergo emergency surgery. Longer hospital stay and excessive intraoperative bleeding have also been reported [2]. Due to the acute nature of intestinal obstruction, sufficient bowel preparation before surgery is not possible, resulting in high incidence (45-50\%) of complication and mortality (15-20\%) [3]. Patients undergoing emergency surgery for acute intestinal obstruction often suffer from serious complications, such as anastomotic rupture, surgical site infection, venous thrombosis, etc [4]. Therefore, the original esophageal stent implantation method used to relieve obstruction accompanying esophageal malignant tumor has been used in obstructive colorectal cancer, which can temporarily relieve intestinal obstruction, making sufficient preoperative preparations possible for the follow up elective surgical resection. 
Many studies have shown [5] that compared to the traditional malignant colorectal obstruction surgery, intestinal stent placement followed by laparoscopic surgery is a safer choice.

Intestinal stent placement is a palliative option proposed by Dohmoto et al [6] in 1990, to relieve symptoms and reduce the need for ostomy surgery. Subsequently, intestinal preparation or palliative treatment by endoscopic intestinal stent implantation followed by limited or elective surgery has gradually attracted the attention of clinicians. Intestinal stent placement followed by laparoscopic surgery has also been reported [7-9] and certain clinical advantages have been realized. However, there is still some controversy regarding the choice of surgical methods and timing during acute obstruction. Some studies have reported that [10] intestinal stent placement followed by laparoscopic surgery have achieved good results in treating malignant intestinal obstruction, such as reducing perioperative mortality while not increasing the occurrence of other complications including anastomotic leakage [11-13]. However, intestinal stent implantation followed by laparoscopic surgery in patients with malignant intestinal obstruction caused by colorectal cancer remains controversial $[14,15]$. Most of the reports are inconclusive. For example, most retrospective studies have small sample sizes. The results of different studies are contradictory to those of one another. Therefore, it is necessary to objectively evaluate the safety and feasibility of treating malignant intestinal obstruction caused by colorectal cancer with endoscopic intestinal stent placement followed by laparoscopic surgery as a surgical option for obstructive colorectal cancer.

\section{Method}

The systematic review and meta-analysis methods used in this study were based on the recommendations of the Preferred Reporting Items for Systematic Reviews and Meta Analyses (PRISMA) statement [16]. Our protocol was registered on the International Platform of Registered Systematic Review and Meta-analysis Protocols database (INPLASY202040171) and is available in full at inplasy.com (https://www.doi.org/10.37766/inplasy2020.4.0171).

A comprehensive search of PubMed, Embase, and Cochrane databases was conducted for the metaanalysis part of the study. A total of 251 relevant publications were retrieved. The inclusion criteria were: (1) patients with obstructive colorectal cancer; (2) studies containing two groups: intestinal stent implantation followed by laparoscopic surgery group and emergency surgery group; and (3) all cases treated with surgery. The clinical criteria included in the study were: (1) perioperative mortality; (2) anastomotic leakage; (3) surgery site infection; (4) length of postoperative hospital stay; (5) operating Time. Exclusion criteria were: (1) acute obstruction caused by non-colorectal cancer; (2) incomplete data; and (3) poor quality of the publication. The databases were searched for all randomized clinical trials (RCT) comparing the two treatment methods or retrospective studies (R) meeting the inclusion and exclusion criteria. Out of the 251 publications retrieved initially, elimination of duplicates and further screening, 11 publications that met our study criteria were included in the present study. This study set of 11 publications includes 6 retrospective research papers and 5 RCT publications. Out of a total of 828 cases included in these studies, 465 were those of stent placement followed by laparoscopy and 363 were those who had undergone emergency surgery. RevMan 5.2 software was used to conduct the meta- 
analysis. The clinical criteria for the analysis were perioperative mortality, anastomotic leakage, infection of surgical incision, operating time, and the length of postoperative hospital stay.

For the retrospective part of the study, select patients admitted to the Shunde Hospital of Southern Medical University between January 2014 and May 2019 for obstructive colorectal cancer and treated either with endoscopic colorectal stent placement followed by laparoscopic surgery or emergency surgery. The study inclusion criteria were: (1) symptoms such as abdominal pain and bloating accompanied by intestinal obstruction as indicated by the complete blockage of anus stopping defecation and exhaust; (2) imaging examinations showing colorectal obstruction; (3) colorectal tumors and intestinal obstruction confirmed during surgery and the surgical pathology report of colorectal adenocarcinoma with TNM staging of T14NO-2M0; and (4) involvement of high rectum. Patients with surgical contraindications were excluded from the emergency surgery group. Abdominal exploration was performed on an elective or emergency basis, and proximal ileostomy. For the endoscopic intestinal stent implantation followed by laparoscopic surgery group, the patient and his family signed a consent form for the endoscopic colorectal stent implantation. Two weeks after the intestinal stent implantation, Dixon surgery or radical left colon resection was performed. SPSS 21 package was used for statistical analysis and processing of the collected data. The statistical results were reported as mean \pm standard deviation $(\overline{\mathrm{x}} \pm \mathrm{s})$, and the numerical results were reported as the number of cases. The $\chi^{2}$ test was used for the comparison of numerical results data, and ttest was used for comparing the statistical analysis results. The t-test was used if the data conformed to the normality test. If the data did not conform to the normality test, the rank sum test was selected, such as age. If the total number of patients $T<40$ cases or each If the number of cases in the group is less than 5 , the Fisher test was chosen, and $P<0.05$ was considered statistically significant difference. The research criteria under study were anastomotic leakage, infection of the incision, perioperative mortality, length of postoperative hospital stay, operating time and the degree of intraoperative bleeding. There were a total of 99 cases in the two groups: 23 in the endoscopic stent placement followed by laparoscopic surgery group and 76 in the emergency surgery group. Informed consent of the patients' family members was required for inclusion in the study.

\subsection{Document retrieval and data collection}

We have searched the PubMed, Embase, and Cochrane databases for our meta-analysis. The search terms were: colorectal cancer, intestinal obstruction, emergency surgery, and stents. The search formula was: ((("malign"[All Fields] OR "malignance"[All Fields] OR "malignances"[All Fields] OR "malignant"[All Fields] OR "malignants"[All Fields] OR "malignities"[All Fields] OR "malignity"[All Fields] OR "malignization"[All Fields] OR "malignized"[All Fields] OR "neoplasms"[MeSH Terms] OR "neoplasms"[All Fields] OR "malignancies"[All Fields] OR "malignancy"[All Fields]) AND ("intestinal obstruction"[MeSH Terms] OR ("intestinal"[All Fields]) OR "intestinal obstruction"[All Fields]) AND ("stents"[All Fields] OR "stentings"[All Fields] OR "stents"[All Fields] OR "stent"[All Fields] OR "stented"[All Fields] OR "stenting"[All Fields])) OR ("colorectal neoplasms" [MeSH Terms] OR ("colorectal"[All Fields]) OR "colorectal neoplasms"[All Fields] OR ("colorectal"[All Fields]) OR "colorectal cancer"[All Fields])) AND ((ffrft[Filter]) AND (books docs[Filter] OR clinical trial[Filter] OR meta-analysis[Filter] OR randomized controlled trial[Filter] OR review[Filter] AND (data[Filter])). All papers 
were screened by two independent investigators using the previously defined inclusion and exclusion criteria. Decision about controversial research was reached through discussion among researchers, and literature search process (Fig. 1.1).

\subsection{Quality Evaluation}

The quality of the publications included in the meta-analysis was scored independently by three reviewers using the Cochrane Risk of Bias Tool or the Newcastle-Ottawa Scale (NOS). The quality evaluation method for the retrospective part of the study used an improved scale [17] (except for RCT). All RCT studies were considered high quality studies. Each study was assigned a score from 0 to 9 . Observational studies that scored 6 points or more were considered high quality studies (Table 1.1).

Table 1.1

Basic information of the studies included in the analysis

\begin{tabular}{|c|c|c|c|c|c|c|}
\hline \multirow[t]{2}{*}{ Study } & \multirow[t]{2}{*}{ Year } & \multirow[t]{2}{*}{ Type } & Patients(n) & \multirow[t]{2}{*}{ Tumor location } & \multirow{2}{*}{$\begin{array}{l}\text { Scoring } \\
\text { index }\end{array}$} & \multirow{2}{*}{$\begin{array}{l}\text { Quality } \\
\text { Score }\end{array}$} \\
\hline & & & SBTS ES & & & \\
\hline Chung Ki Min et al. & 2016 & $\mathrm{R}$ & 7024 & $\begin{array}{l}\text { Left half of } \\
\text { intestine }\end{array}$ & $1,2,3,4,7$ & 5 \\
\hline Gil Jae Lee et al. & 2013 & $\mathrm{R}$ & 4928 & $\begin{array}{l}\text { Left half of } \\
\text { intestine }\end{array}$ & $1,2,3,4,7,8$ & 6 \\
\hline Hun Jin Kim et al. & 2013 & $\mathrm{R}$ & 4348 & $\begin{array}{l}\text { Left half of } \\
\text { intestine }\end{array}$ & $1,2,3,4,6,7,8$ & 7 \\
\hline Sun Jin Park et al. & 2015 & $\mathrm{R}$ & 6735 & $\begin{array}{l}\text { Left half of } \\
\text { intestine }\end{array}$ & $1,2,4,7$ & 4 \\
\hline Hooft et al. & 2017 & $\mathrm{RCT}$ & 4751 & $\begin{array}{l}\text { Left half of } \\
\text { intestine }\end{array}$ & - & $\mathrm{RCT}$ \\
\hline Van den Berg et al. & 2014 & $\mathrm{RCT}$ & 4234 & $\begin{array}{l}\text { Left half of } \\
\text { intestine }\end{array}$ & - & $\mathrm{RCT}$ \\
\hline Emma Oistamo et al. & 2016 & $\mathrm{RCT}$ & 2757 & $\begin{array}{l}\text { Left half of } \\
\text { intestine }\end{array}$ & - & $\mathrm{RCT}$ \\
\hline $\begin{array}{l}\text { Naotsugu Haraguchi } \\
\text { et al. }\end{array}$ & 2016 & $\mathrm{R}$ & 2222 & Rectum & $1,2,3,4,6,7,8$ & 7 \\
\hline Jesse Yu Tajima et al. & 2020 & $\mathrm{R}$ & 5421 & Rectum & $1,2,3,4,6,7$ & 6 \\
\hline Kok Sun et al. & 2012 & $\mathrm{RCT}$ & 2019 & $\begin{array}{l}\text { Left half of } \\
\text { intestine }\end{array}$ & - & $\mathrm{RCT}$ \\
\hline Cheung Hester et al. & 2009 & $\mathrm{RCT}$ & 2424 & $\begin{array}{l}\text { Left half of } \\
\text { intestine }\end{array}$ & - & $\mathrm{RCT}$ \\
\hline
\end{tabular}


Scoring indicators: 1 - age; 2 - gender; 3 - tumor location; 4 - complications; 5 - adjuvant chemotherapy; 6 tumor size; 7 - tumor stage; 8 - body mass index; 9 - anatomical complexity

\subsection{Data Analysis}

RevMan 5.2 statistical analysis software was used for data analysis, and $\chi^{2}$ test and $\mathrm{I}^{2}$ test were used for heterogeneity evaluation. When $P>0.1$ and $P^{2}<50 \%$, we concluded that there was no significant heterogeneity in the study, and a fixed-effects model was used. When $P<0.1$ and $R>50 \%$, we concluded that the study showed heterogeneity and the random effects model was selected for the analysis. The identified heterogeneity was further analyzed. Using odds ratio (OR) to describe numerical data, we calculated the $95 \%$ confidence interval $(\mathrm{Cl})$ for all the numerical data. $P<0.05$ was considered meaningful.

\section{Results}

\subsection{Results of meta-analysis}

\subsubsection{Anastomotic fistula}

Data from eight publications were analyzed for this study criterion [18-25]. Since there was no significant heterogeneity $\left(P=0.81, I^{2}=0 \%\right)$ fixed effects model was used. The results of the meta-analysis [OR was 0.88 (95\% Cl: $0.46-1.67, \mathrm{P}=0.69)]$. showed that compared to emergency surgery, intestinal stent implantation followed by laparoscopic surgery did not increase the incidence of anastomotic leakage (Fig. 2.1.1).

\subsubsection{Perioperative mortality}

Data from eight publications were used for analyzing this study criterion [19-21, 23-27]. Since there was no significant heterogeneity $\left(P=0.73, l^{2}=0 \%\right)$, fixed effects model was adopted. The results of the metaanalysis [OR was $0.46(95 \% \mathrm{Cl}: 0.22-0.95, \mathrm{P}=0.04)$ ] showed that compared to emergency surgery, intestinal stent placement followed by laparoscopic surgery reduced the incidence of perioperative mortality (Fig. 2.1.2).

\subsubsection{Postoperative infection}

Data from six publications were analyzed for this study criterion [19-24]. Since there was no significant heterogeneity $\left(P=0.62, l^{2}=0 \%\right)$, fixed effects model was adopted. The meta-analysis results [OR was 0.44 (95\% Cl: $0.24-0.82, \mathrm{P}=0.009)$ ] showed that compared to emergency surgery, colonic stent placement by laparoscopic surgery can reduce the incidence of postoperative wound infection (Fig. 2.1.3).

\subsubsection{Operating time}

Data from three publications were analyzed for this study criterion $[19,25,28]$. Since there was no significant heterogeneity $\left(P=0.96, I^{2}=19 \%\right)$, fixed effects model was used. The meta-analysis results [MD was 0.56 (95\% Cl: -21.79-22.91, $\mathrm{P}=0.96)$ ]. showed that compared to emergency surgery, colorectal stent implantation followed by laparoscopic surgery did not increase the operating time (Fig. 2.1.4). 


\subsubsection{Length of postoperative hospital stay}

Data from two publications were analyzed for this study criterion $[19,25]$. Since there was no significant heterogeneity $\left(P=0.22, I^{2}=32 \%\right)$, fixed effects model was adopted. The meta-analysis results [MD is -2.07 (95\% Cl: $-2.55--1.59, \mathrm{P}<0.00001)$ ] showed that compared to emergency surgery, colorectal stent implantation followed by laparoscopic surgery can shorten the length of postoperative hospital stay (Fig. 2.1.5).

\subsubsection{Results of subgroup analysis}

We considered the possibility that difference in the surgical sites may lead to differences in the surgical outcomes due to anatomical factors. Therefore, procedures involving left colon and rectum were subjected to a subgroup analysis. The results of the anastomotic leakage study showed that in the case of left colon and high rectum, there was no significant difference between emergency surgery and intestinal stent implantation followed by laparoscopy $(P=0.26$ and $P=0.77)$. However, there was a significant difference between the two methods as far as the incidence of postoperative incision infection was concerned in procedures involving left colon $(P=0.01)$. There was no significant difference between the two surgical methods in procedures involving high rectum (Table 2.1).

Table 2.1 Subgroup analysis results of intestinal stent placement followed by laparoscopic surgery and emergency surgery group

Research criterion

\begin{tabular}{|c|c|c|c|c|}
\hline & ES & OR $₫ 95 \% \mathrm{Cl} \otimes$ & $P$ & Subgroup \\
\hline
\end{tabular}

Anastomotic fistula (n)

Left colon

$16 \quad 18$

$0.67 \rrbracket 0.34 \rrbracket$
$1.34 \rrbracket$

0.26

$\begin{array}{cc}0.62 & 1 \\ 0.43 & \end{array}$

0

High rectum

84

$\begin{array}{ll}4 & 1.21 \rrbracket 0.07 \rrbracket \\ & 2.76 \rrbracket\end{array}$

$0 . .77$

Postoperative infection

(n)

$\begin{array}{lllll}\text { Left colon } & 17 & 25 & \begin{array}{l}0.44 \llbracket 0.23 \rrbracket \\ 0.85 \rrbracket\end{array} & 0.01 \\ \text { High rectum } & 2 & 4 & \begin{array}{l}0.45 \rrbracket 0.07 \rrbracket \\ 2.76 \rrbracket\end{array} & 0.39 \\ & & & & \end{array}$

\subsubsection{Results of the funnel chart analysis}

Results of the funnel chart analysis of the five study criteria are shown below. The results suggest that they are not completely symmetrical, and there may be publication bias. Fig. 2.1.6 (a, b, c, d, e) 
2.2 Retrospective analysis of the outcomes of intestinal stent placement followed by laparoscopic surgery and emergency surgery at our center

Surgical outcomes of 99 patients comprising 51 males and 48 females, who were admitted to our center were analyzed in the retrospective analysis part of the study. There were 23 patients in the endoscopic intestinal stent placement followed by laparoscopic surgery (SBTS) group and 76 patients in the emergency surgery (ES) group. The average age of the SBTS group was $(58.17 \pm 16.03)$ years; the average age of the ES group was $(63.87 \pm 13.84)$ years. There was no significant difference in age and gender between the two groups $(P>0.05)$. Among the patients in SBTS group, 8 were in stage II and 15 in stage III; 16 cases involved left colon and 7 cases involved rectum. Among the patients in ES group, 25 were in stage II and 51 in stage III; 52 cases involved left colon and 24 cases involved rectum. The SBTS group and the ES group were not statistically different in gender, age, tumor location, and clinical staging indicators $(P>0.05)$, (Table 2.2).

Table 2.2

Comparison of baseline data between the two groups $\left(\chi^{2} / \mathrm{t}\right)$

\begin{tabular}{|lllllll|}
\hline Group & $\begin{array}{l}\text { Anastomotic } \\
\text { fistula }\end{array}$ & $\begin{array}{l}\text { Incision } \\
\text { infection }\end{array}$ & $\begin{array}{l}\text { Perioperative } \\
\text { mortality }\end{array}$ & $\begin{array}{l}\text { Operating } \\
\text { time (min) }\end{array}$ & $\begin{array}{l}\text { Postoperative } \\
\text { hospital } \\
\text { stay(d) }\end{array}$ & $\begin{array}{l}\text { Surgical } \\
\text { bleeding(ml) }\end{array}$ \\
\hline SBTS & 2 & 2 & 0 & $204.13 \pm 37.35$ & $12.91 \pm 5.47$ & $155.65 \pm 94.90$ \\
\hline ES & 9 & 22 & 3 & $245.11 \pm 18.15$ & $16.92 \pm 8.71$ & $237.11 \pm 57.82$ \\
$\chi^{2} / t$ & 0.18 & 3.94 & 0.94 & 5.08 & 2.64 & 3.90 \\
\hline$P$ & 0.67 & 0.04 & 0.33 & 0.00 & 0.01 & 0.001 \\
\hline
\end{tabular}

In the intestinal stent implantation followed by laparoscopic surgery group, 2 cases of intestinal perforation occurred after stent implantation and were switched to emergency surgery (not included in the study). The success rate of stent placement was $92 \%$. After intestinal stent placement, the patient's clinical manifestations such as abdominal pain and bloating were significantly relieved, and laparoscopic surgery was performed 2 weeks later.

2.2.1 There were 2 instances (8.7\%) of incision infection in the intestinal stent implantation followed by laparoscopic surgery group, while there were 22 instances $(28.9 \%)$ in the emergency surgery group $\left(\chi^{2}=\right.$ $3.94, \mathrm{P}=0.04)$. The difference in the index of incision infection between the two groups was statistically significant $(P<0.05)$.

2.2.2 Intestinal stent placement followed by laparoscopic surgery group had two instances of anastomotic leakage (8.7\%), and the emergency surgery group had 9 instances $(11.8 \%)\left(\chi^{2}=0.18, P=0.67\right)$. The difference between the two groups in the index of anastomotic leakage was not statistically significant $(P>0.05)$. 
2.2.3 No patient treated by the method of intestinal stent implantation followed by laparoscopic surgery group died during the perioperative period, (3.9\%) cases died in the emergency surgery group $\left(\chi^{2}=0.94\right.$, $\mathrm{P}=0.33)$. The difference between the two groups in the index of perioperative mortality was not statistically significant $(P>0.05)$.

2.2.4 The operating time for intestinal stent implantation followed by laparoscopic surgery group was $204.13 \pm 37.35 \mathrm{~min}$ which was less than that for the emergency surgery group $(245.11 \pm 18.15 \mathrm{~min})(t=5.08$, $\mathrm{P}=0.000)$. The difference between the two groups in the index of operating time was statistically significant $(P<0.05)$.

2.2.5 Intestinal stent implantation followed by laparoscopic surgery group had intraoperative blood loss of $155.65 \pm 94.90 \mathrm{ml}$, which was less than that in the emergency surgery group $(237.11 \pm 57.82 \mathrm{ml})(\mathrm{t}=3.90$, $P=0.001)$. The difference between the two groups in the index of intraoperative blood loss was statistically significant $(P<0.05)$.

2.2.6 The length of the postoperative hospital stay in the intestinal stent followed by laparoscopic surgery group was $12.91 \pm 5.47$ days, which was shorter than that of the emergency surgery group $(16.92 \pm 8.71$ days) ( $(=2.64, P=0.01)$. The difference between the two groups in the index of postoperative hospital stay was statistically significant $(P<0.05)$ (Table 2.3$)$.

Table 2.3

Comparison of the surgical outcomes between the SBTS group (23 patients) and the ES group (76 Patients).

\begin{tabular}{|lllllll|}
\hline Group & $\begin{array}{l}\text { Anastomotic } \\
\text { fistula }\end{array}$ & $\begin{array}{l}\text { Incision } \\
\text { infection }\end{array}$ & $\begin{array}{l}\text { Perioperative } \\
\text { mortality }\end{array}$ & $\begin{array}{l}\text { operating } \\
\text { time (min) }\end{array}$ & $\begin{array}{l}\text { Postoperative } \\
\text { hospital stay } \\
\text { (d) }\end{array}$ & $\begin{array}{l}\text { Blood } \\
\text { loss(ml) }\end{array}$ \\
\hline SBTS & 2 & 2 & 0 & $204.13 \pm 37.35$ & $12.91 \pm 5.47$ & $155.65 \pm 94.90$ \\
\hline ES & 9 & 22 & 3 & $245.11 \pm 18.15$ & $16.92 \pm 8.71$ & $237.11 \pm 57.82$ \\
\hline$\chi^{2} / t$ & 0.18 & 3.94 & 0.94 & 5.08 & 2.64 & 3.90 \\
\hline$P$ & 0.67 & 0.04 & 0.33 & 0.00 & 0.01 & 0.001 \\
\hline
\end{tabular}

\section{Discussion}

Colorectal cancer is a common malignant tumor of the gastrointestinal system. 7-28\% of Colorectal cancer patients have complete or partial intestinal obstruction as the earliest symptom [1]. Emergency surgery is the conventional treatment for these patients. However, due to the many complications of emergency surgery, intestinal stent implantation followed shortly thereafter by laparoscopic surgery is drawing significant attention.

\subsection{Anastomotic fistula}

Anastomotic fistula is a serious complication of colorectal malignant tumor with intestinal obstruction, which aggravates the patient's suffering, endangers the patient's life, prolongs the hospital stay, increases medical expenses, and reduces the patient's postoperative quality of life. Although some anastomotic 
fistulas are effectively treated conservatively, the cure rate is only about $50 \%$. About $50 \%$ of patients require surgery [29]. Therefore, it is very important to prevent postoperative anastomotic leakage. Studies have shown [10] that intestinal stent implantation followed by elective surgery does not increase the risk of anastomotic leakage, which is consistent with the results of this study. The results of the meta-analysis part of this study showed that the frequency of anastomotic leakage was comparable between the two methods - intestinal stent placement followed by laparoscopic surgery and emergency surgery $(P=0.69)$. In addition, meta-analysis study also compared the two methods with respect to left colon and rectum in consideration of the possible bias the anatomical position of the surgery may introduce. The results of the anastomotic leakage study showed that there was no significant difference between the two methods in the high rectum ( $P=0.26$ and $P=0.77)$. The results of the retrospective study of patients treated at our center also confirmed that there was no significant difference between the two methods with respect to in anastomotic leakage $(P=0.67)$. We therefore believe that compared to emergency surgery, colorectal stent implantation followed by laparoscopic surgery does not increase the incidence of anastomotic leakage.

\subsection{Perioperative mortality}

Malignant bowel obstruction caused by colorectal cancer often requires emergency surgery. The perioperative mortality rate during emergency surgery is as high as $15-20 \%$ [1]. Some studies have reported [15] that endoscopic intestinal stent placement as a bridge to perform laparoscopic surgery within a limited period thereafter not only reduced perioperative mortality, but also reduced postoperative complications. The results of the meta-analysis of this study showed that there was a significant difference in perioperative mortality $(P=0.04)$ between the two groups undergoing either emergency surgery or stent implantation followed by laparoscopic resection. However, our retrospective study showed that there was no significant difference in perioperative mortality $(P=0.33)$ between the two groups. The small sample size included in the retrospective analysis and the fact that it is a single center study might have biased the results. Since the meta-analysis sample size was significantly larger, in spite of the results of the retrospective part of the study, we believe that intestinal stent implantation followed by laparoscopic surgery can reduce the perioperative mortality of patients compared to emergency surgery and can be of significant benefit to patients.

\subsection{Postoperative wound infection}

Traditionally, the overall complication rate after emergency surgery has been higher. The problems resulting from these complications seriously affect the quality of life and cost of living of patients with colorectal cancer. Meta-analysis results of this study showed that the rate of postoperative wound infection ( $P=0.009)$ was significantly higher in emergency surgery. Subgroup analysis of procedures involving left colon and rectum were carried out to identify any bias introduced by the differences in the anatomical position of the obstruction. This subgroup analysis also showed significant difference between the two methods with respect to postoperative wound infection $(P=0.01)$. The difference was not significant in the case of high rectum. We believe that the small sample size of high rectum cases might be the reason for this result. The retrospective study results of cases treated at our center showed a significant difference between the two methods $(P=0.04)$. We believe that compared to emergency surgery, 
colorectal stent placement followed by laparoscopic surgery reduces the incidence of postoperative wound infection.

\subsection{Operating time and blood loss}

For patients with colorectal tumors and malignant intestinal obstruction, shortening the operating time and reducing the amount of intraoperative blood loss have an important impact on the prognosis. We retrospectively studied the cases treated at our center and showed that compared to the emergency surgery group, the operating time and blood loss were significantly lower $(P<0.05)$ during intestinal stent implantation followed by laparoscopic surgery. The meta-analysis results of this study showed that there was no significant difference in the operating time between the two groups of patients $(P=0.96)$. It is not possible to prepare the intestinal tract adequately immediately prior to emergency surgery, which is not the case with SBTS procedure. Bowel irrigation prior to SBTS takes a certain amount of time, which may not have been included in the total operating time for the emergency surgery resulting in bias. Therefore, we believe that compared to emergency surgery, Intestinal stent implantation followed by laparoscopic surgery does not increase the total operating time.

\subsection{Length of postoperative hospital stay}

The length of the hospital stay after the surgery affects the treatment and contributes to the economic burden of the patient. The meta-analysis results of this study showed that there was a statistically significant difference between the two methods in the length of the postoperative hospital stay $(P<0.00001)$. The results of our retrospective study confirm this inference $(P=0.01)$. We therefore conclude that compared to the emergency surgery, intestinal stent implantation followed by laparoscopic surgery can shorten the postoperative hospital stay.

Our results show that intestinal stent Implantation followed by laparoscopic surgery can reduce perioperative mortality, postoperative wound infection, and shorten postoperative hospital stay. In addition, compared to emergency surgery, it does not increase the risk of anastomotic leakage and can reduce intraoperative bleeding. However, whether stent placement will cause tumor metastasis remains to be confirmed. This is an important factor and hence the complications of stent placement should be considered carefully during decision making. The fact that some patients who have received stent placement do not undergo surgery for various reasons cannot be ignored These patients may have complications such as bleeding, stent migration, perforation, blockage recurrence, tumor metastasis, etc. $[4,30]$. Therefore, this is also a factor that should be considered before stent placement.

In short, in colorectal cancer and malignant intestinal obstruction, compared to emergency surgery, intestinal stent implantation followed by laparoscopic surgery within a short period reduces postoperative wound infection, perioperative mortality, intraoperative blood loss, and shortens postoperative hospital stay. In addition, it makes one-stage anastomosis possible and allows the selection of optimal window period for laparoscopic surgery based on the patient's condition. Therefore, preoperative stent insertion followed by laparoscopic surgery shortly thereafter is an effective alternative to emergency surgery for 
malignant colonic obstruction. The results of this study indicate that intestinal stent implantation followed by laparoscopic surgery is safe and feasible.

\section{Abbreviations}

SBTS = Intestinal Stent Implantation followed by Laparoscopic Surgery

$\mathrm{ES}=$ Emergency Surgery

RCT = Randomized Clinical Trial

R=Review

\section{Declarations}

Funding:

This research was funded by 2021 Special Innovation Project of Guangdong Provincial Department of Education (No. 2021KTSCX015) \In-depth promotion of the innovation-driven assistance project in Foshan City (No. 2021043) 区the 2018 Foshan City Outstanding Young Medical Talent Training Project (No. 600009) $₫ 2020$ Shunde District Competition Support Talent Project (no serial number) \Southern Medical University Shunde Hospital Scientific Research Startup Plan (No. SRSP2018001) 『Guangdong Medical Science and Technology Research Fund Project (No. A2019302) \the Science and Technology Plan Project of Foshan Science and Technology Bureau (No. 2018AB000683) खNational Natural Science Foundation of China, National Natural Science Youth Fund Project (No. 81802879)『Southern Medical University Scientific Research Startup Plan (No. PY2018N110) and Foshan City's 13th Five-Year Key Specialty Project (FSGSP2D135051).

Authors' contributions:

MZOY is responsible for the concept and design of this research. ZWL retrieved the data. ZWL, YL and WK analyzed and interpreted the data. MZOY and ZWL drafted and revised the manuscript. TYL verified the analytical methods. YLJ put forward critical suggestions for the revision. YHP participated in manuscript writing and partial data collection. All authors approved the submitted version.

Availability of data and materials:

The data and materials are available on reasonable request from the corresponding. The data has been uploaded to the public data platform (https://www. figshare.com $\otimes$. The doi number is $10.6084 / \mathrm{m} 9$. figshare.17693726.

Declarations

Competing interests: 
The authors declare that they have no competing interests.

Ethics approval and consent to participate:

This study was conducted in accordance with the guidelines and regulations of the Medical Ethics Committee of Shunde Hospital Affiliated to Southern Medical University. The ethics committee of Shunde Hospital affiliated to Southern Medical University approved the study. All participants in this study gave written informed consent.

Consent for publication:

All participants in this study gave consent to publish.

Acknowledgements:

Not applicable.

\section{References}

1. Smothers L, Hynan L, Fleming J, et al. Emergency surgery for colon carcinoma. Dis Colon Rectum 2003, 46:24-30. https://doi.org/10.1007/s10350-004-6492-6

2. Zhao JK, Chen NZ, Zheng JB, He S, Sun XJ. Laparoscopic versus open surgery for rectal cancer: Results of a systematic review and meta-analysis on clinical efficacy. Mol Clin Oncol. 2014 Nov;2(6):1097-1102. https://doi.org/10.1097/01.sla.0000130723.81866.75

3. Paris P.Tekkis M, FRCS, Robin Kinsman, et al. The Association of Coloproctology of Great Britain and Ireland Study of Large Bowel Obstruction Caused by Colorectal Cancer. Ann. Surg. 2004 Jul;240(1):76-81. https://doi.org/10.1097/01.sla.0000130723.81866.75

4. Olmi S, Scaini A, et al. Acute colonic obstruction: endoscopic stenting and laparoscopic resection. Surg Endosc. 2007 Nov;21(11):2100-2104. https://doi.org/10.1007/s00464-007-9352-3

5. Yi Zhang, Jian Shi, et al. Self-expanding metallic stent as a bridge to surgery versus emergency surgery for obstructive colorectal cancer: a meta-analysis. Surg Endosc. 2012 Jan;26(1):110-119. https://doi.org/10.1007/s00464-011-1835-6

6. M Dohmoto, K D Rupp, G Hohlbach. Endoscopically-implanted prosthesis in rectal carcinoma. Dtsch Med Wochenschr.1990 Jun 8;115(23):915.

7. Saida Y, Sumiyama Y, Nagao J, et al. Long-term prognosis of preoperative "bridge to surgery" expandable metallic stent insertion for obstructive colorectal cancer: comparison with emergency operation. Dis Colon Rectum. 2003;46: S44-S49. https://doi.org/10.1097/01.dcr.0000087483.63718.a2

8. Zhao XD, Cai BB, Cao RS, et al. Palliative treatment for incurable malignant colorectal obstructions: a meta-analysis. World J Gastroenterol. https://doi.org/10.3748/wjg.v19.i33.5565 
9. Cirocchi R, Farinella E, Trastulli S, et al. Safety and efficacy of endoscopic colonic stenting as a bridge to surgery in the management of intestinal obstruction due to left colon and rectal cancer: a systematic review and meta-analysis. Surg Oncol. 2013; 22:14-21. https://doi.org/10.1016/j.suronc.2012.10.003

10. Wang $X, H e J$, Chen $X$, et al. Stenting as a bridge to resection versus emergency surgery for left-sided colorectal cancer with malignant obstruction: A systematic review and meta-analysis. Int J Surg. 2017 Dec;48:64-68. https://doi.org/10.1016/j.ijsu.2017.10.004

11. Lee GJ, Kim HJ, Baek JH, et al. Comparison of short-term outcomes after elective surgery following endoscopic stent insertion and emergency surgery for obstructive colorectal cancer. Int J Surg 2013;11(6):442-446. https://doi.org/10.1016/j.ijsu.2013.04.010

12. Mulcahy HE, Skelly MM, Husain A, et al. Long-term outcome following curative surgery for malignant large bowel obstruction. Br J Surg 1996 Jan;83(1):46-50. https://doi.org/10.1002/bjs.1800830114

13. Zheng $\mathrm{C}, \mathrm{Wu} \mathrm{YL}$, Li Q. Preoperative intestinal stent decompression with primary laparoscopic surgery to treat left-sided colorectal cancer with obstruction: a report of 21 cases. Cancer Biol Med 2013 Jun;10(2):99-102. https://doi.org/10.7497/j.issn.2095-3941.2013.02.006

14. Frago R, Ramirez E, Millan M, et al. Current management of acute malignant large bowel obstruction: a systematic review. Am J Surg 2014 Jan;207(1):127-138. https://doi.org/10.1016/j.amjsurg.2013.07.027

15. van Hooft JE, Bemelman WA, Oldenburg B, et al. Colonic stenting versus emergency surgery for acute left-sided malignant colonic obstruction: a multicentre randomised trial. Lancet Oncol $2007 \mathrm{Jul}$ 3(7):12-16. https://doi.org/10.1186/1471-2482-7-12

16. Moher $D$, Shamseer $L$, Clarke $M$, et al. Preferred reporting items for systematic review and metaanalysis protocols (PRISMA-P) 2015 statement. Syst Rev 2015; 4:1. https://doi.org/10.1186/20464053-4-1

17. G. Wells CDO, J. Peterson, V. Welch, et al. The Newcastle-Ottawa Scale (NOS) for Assessing the Quality of Nonrandomised Studies in Meta-Analyses Ottawa Hospital Research Institute Web Site;2018

18. Tajima JY, Matsuhashi N, Takahashi T,et al. Short- and long-term outcomes after colonic selfexpandable metal stent placement for malignant large-bowel obstruction as a bridge to surgery focus on the feasibility of the laparoscopic approach: a retrospective, single center study. World J Surg Oncol. 2020 Oct 13;18(1):265-269. https://doi.org/10.1186/s12957-020-02039-8

19. Lee GJ, Kim HJ, Baek JH, et al. Comparison of short-term outcomes after elective surgery following endoscopic stent insertion and emergency surgery for obstructive colorectal cancer. Int J Surg. 2013;11(6):442-446. https://doi.org/10.1016/j.ijsu.2013.04.010

20. van Hooft JE, Bemelman WA, Breumelhof R,et al. Colonic stenting as bridge to surgery versus emergency surgery for management of acute left-sided malignant colonic obstruction: a multicenter randomized trial (Stent-in 2 study). BMC Surg. 2007 Jul 3(7):12-18. https://doi.org/10.1186/14712482-7-12 
21. van den Berg MW, Sloothaak DA, Dijkgraaf MG,etal. Bridge-to-surgery stent placement versus emergency surgery for acute malignant colonic obstruction. Br J Surg. 2014 Jun;101(7):867-873. https://doi.org/10.1002/bjs.9521

22. Haraguchi N, Ikeda M, Miyake M,et al. Colonic stenting as a bridge to surgery for obstructive colorectal cancer: advantages and disadvantages. Surg Today. 2016 Nov;46(11):1310-1317. https://doi.org/10.1007/s00595-016-1333-5

23. Kim HJ, Huh JW, Kang WS, et al. Oncologic safety of stent as bridge to surgery compared to emergency radical surgery for left-sided colorectal cancer obstruction. Surg Endosc. 2013 Sep;27(9):3121-3128. https://doi.org/10.1007/s00464-013-2865-z

24. Park SJ, Lee KY, Kwon SH, et al. Stenting as a Bridge to Surgery for Obstructive Colon Cancer: Does It Have Surgical Merit or Oncologic Demerit? Ann Surg Oncol. 2016 Mar;23(3):842-848. https://doi.org/10.1245/s10434-015-4897-1

25. Min CK, Kim HO, Lee D, et al. Obstructive Left Colon Cancer Should Be Managed by Using a Subtotal Colectomy Instead of Colonic Stenting. Ann Coloproctol. 2016 Dec;32(6):215-220. https://doi.org/10.3393/ac.2016.32.6.215

26. Oistamo E, Hjern F, Blomqvist L, et al. Emergency management with resection versus proximal stoma or stent treatment and planned resection in malignant left-sided colon obstruction. World J Surg Oncol.2016 Aug 30;14(1):232. https://doi.org/10.1186/s12957-016-0994-2

27. Ho KS, Quah HM, Lim JF, et al. Endoscopic stenting and elective surgery versus emergency surgery for left-sided malignant colonic obstruction: a prospective randomized trial. Int J Colorectal Dis. 2012 Mar,27(3):355-362. https://doi.org/10.1007/s00384-011-1331-4

28. Cheung HY, Chung CC, Tsang WW, et al. Endolaparoscopic approach vs conventional open surgery in the treatment of obstructing left-sided colon cancer: a randomized controlled trial. Arch Surg. 2009 Dec;144(12):1127-1132. https://doi.org/10.1007/s00384-011-1331-4

29. Mulcahy HE, Skelly MM, Husain A, et al. Long-term outcome following curative surgery for malignant large bowel obstruction. Br J Surg.1996 Jan;83(1):46-50. https://doi.org/10.1002/bjs.1800830114

30. Suh JP, Kim SW, Cho YK, et al. Effectiveness of stent placement for palliative treatment in malignant colorectal obstruction and predictive factors for stent occlusion. Surg Endosc.2010 Feb;24(2):400406. https://doi.org/10.1007/s00464-009-0589-x

\section{Figures}




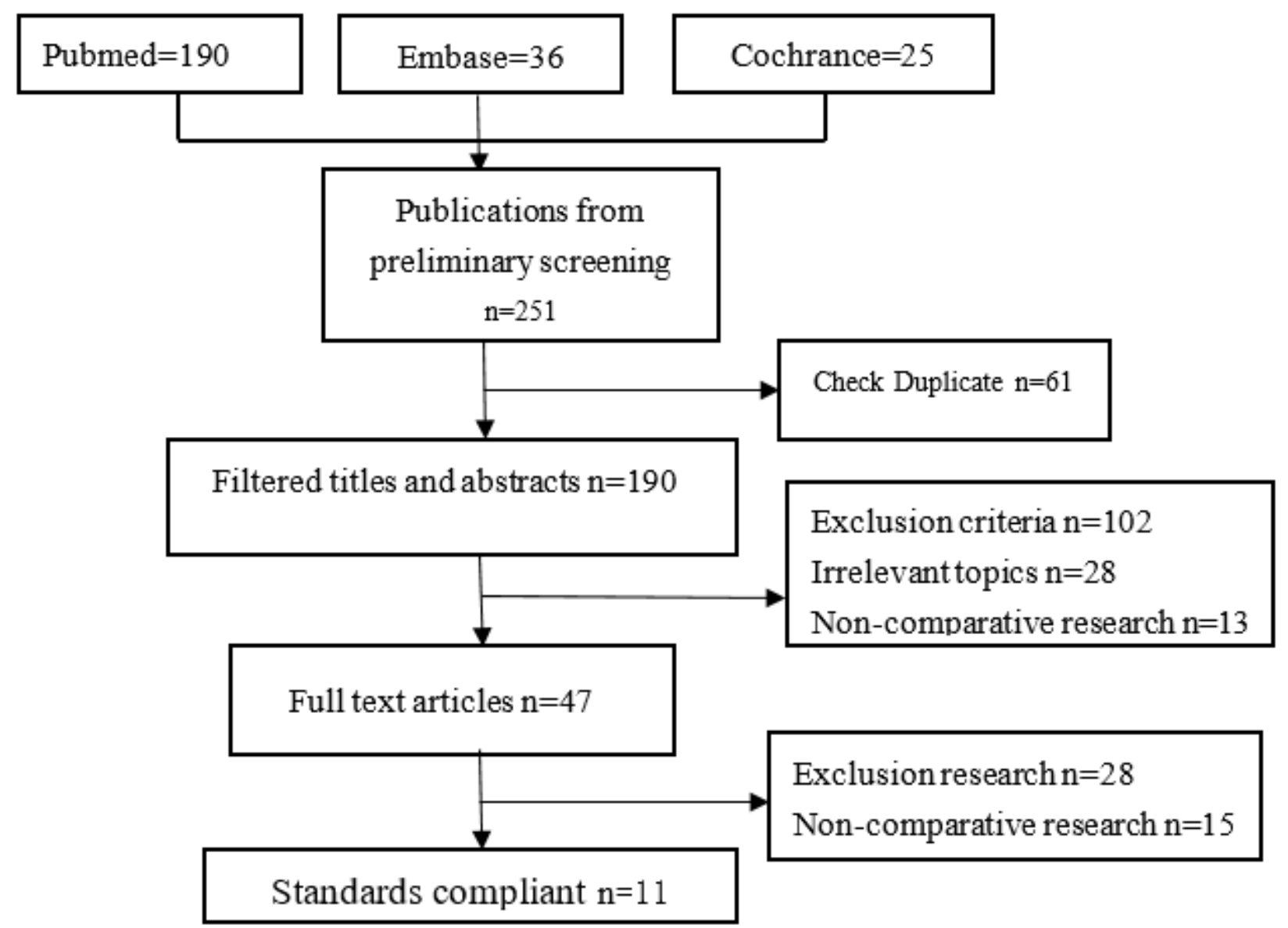

Figure 1

Flow chart of literature screening

Anastomotic fistula

SBTS ES Odds Ratio $\quad$ Odds Ratio

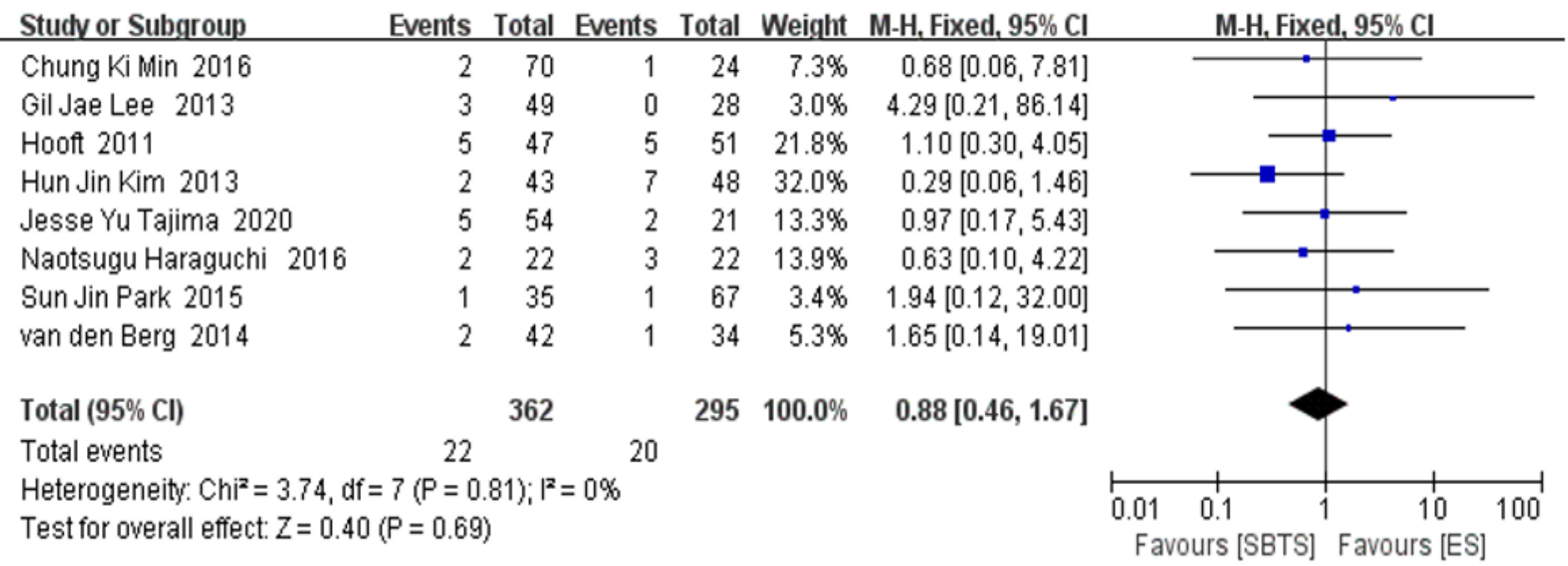


Figure 2

Forest plot of anastomotic leakage in colorectal cancer with malignant obstruction undergoing stent implantation followed by laparoscopic surgery and emergency surgery

\section{Perioperative mortality}

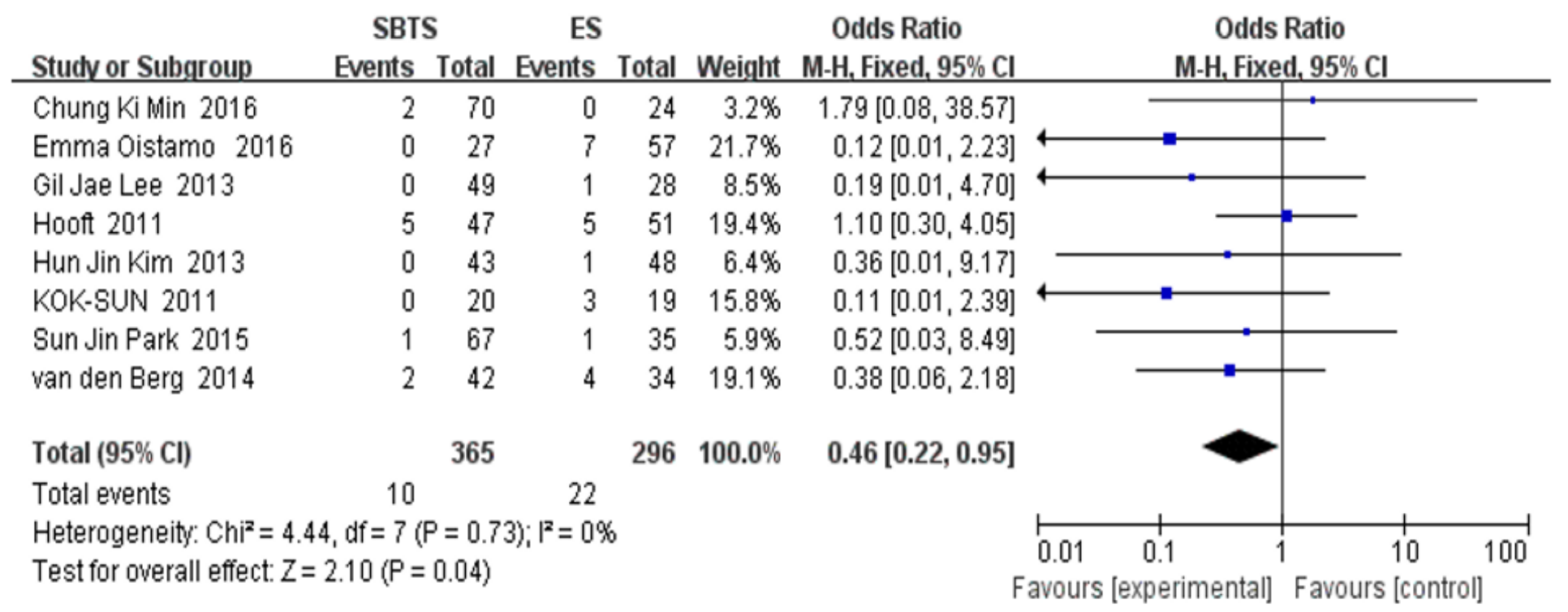

Figure 3

Forest plot of perioperative mortality in patients with malignant obstruction of colorectal cancer undergoing stent implantation followed by laparoscopic surgery and emergency surgery

\section{Postoperative wound infection}

$\begin{array}{llll}\text { SBTS } & \text { Odds Ratio } & \text { Odds Ratio }\end{array}$ Studv or Subgroup

Gil Jae Lee 2013

Hooft 2011

Hun Jin Kim 2013

Naotsugu Haraguchi 2016

Sun Jin Park 2015

van den Berg 2014

Events Total Events Total Weight M-H, Fixed, 95\% Cl

Total $(95 \% \mathrm{Cl})$

Total events

149

$3 \quad 47$

343

222

867

242

028

$451 \quad 11.7 \%$

4

$48 \quad 11.5 \%$

$4 \quad 22 \quad 11.9 \%$

$13 \quad 35 \quad 49.1 \%$

$4 \quad 34 \quad 13.8 \%$

$1.76[0.07,44.74]$

$0.80[0.17,3.78]$

$0.82[0.17,3.91]$

$0.45[0.07,2.76]$

$0.23[0.08,0.63]$

$0.38[0.06,2.18]$

$218 \quad 100.0 \% \quad 0.44[0.24,0.82]$

Heterogeneity: $\mathrm{Chi}^{2}=3.54, \mathrm{df}=5(\mathrm{P}=0.62) ; \mathrm{I}^{2}=0 \%$

Test for overall effect: $Z=2.60(P=0.009)$

\section{M-H, Fixed, 95\% Cl}

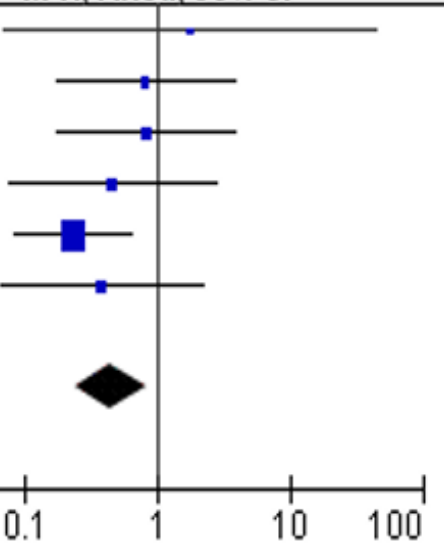

Favours [SBTS] Favours [ES] 
Figure 4

Forest plot of postoperative incision infection in patients with colorectal cancer and malignant intestinal obstruction undergoing intestinal stent implantation followed by laparoscopic surgery and emergency surgery

\section{Operating time}

\begin{tabular}{|c|c|c|c|c|c|c|c|c|c|}
\hline \multirow[b]{2}{*}{ Study or Subgroup } & \multicolumn{3}{|c|}{ SBTS } & \multicolumn{2}{|r|}{ ES } & \multicolumn{3}{|r|}{ Mean Difference } & \multirow{2}{*}{$\begin{array}{l}\text { Mean Difference } \\
\mathrm{N}, \text { Fixed, } 95 \% \mathrm{Cl}\end{array}$} \\
\hline & Mean & SD & Total & Mean & SD & Total & Weight & $\mathrm{N}$, Fixed, $95 \% \mathrm{Cl}$ & \\
\hline Cheung Hester 2009 & 170.5 & 69 & 24 & 188.75 & 56.25 & 24 & $39.4 \%$ & $-18.25[-53.87,17.37]$ & \\
\hline Gil Jae Lee 2013 & 263.3 & 127.5 & 49 & 235.4 & 77.5 & 28 & $23.8 \%$ & $27.90[-17.91,73.71]$ & \\
\hline Hooft 2011 & 138 & 125 & 47 & 135 & 32.5 & 51 & $36.8 \%$ & $3.00[-33.83,39.83]$ & \\
\hline Total (95\% Cl) & & & 120 & & & 103 & $100.0 \%$ & $0.56[-21.79,22.91]$ & \\
\hline $\begin{array}{l}\text { Heterogeneity: } \mathrm{Chi}^{2}=2 \\
\text { Test for overall effect: } Z\end{array}$ & $\begin{array}{l}46, d f= \\
=0.05(-1\end{array}$ & & 29); $\left.\right|^{2}=$ & $19 \%$ & & & & & $\begin{array}{ccccc}-100 & -50 & 0 & 50 & 100 \\
\text { Favours [SBTS] } & \text { Favours [ES] }\end{array}$ \\
\hline
\end{tabular}

\section{Figure 5}

Forest plot of the operating time for intestinal stent implantation followed by laparoscopic surgery and emergency surgery in patients with colorectal cancer and malignant intestinal obstruction

\section{Length of postoperative hospital stay}

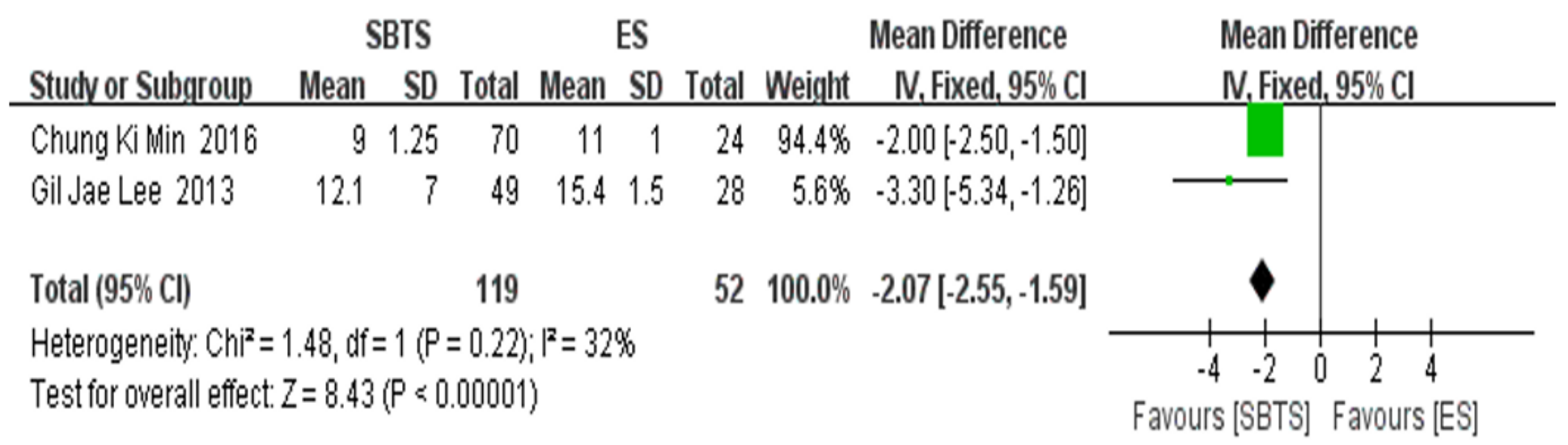

\section{Figure 6}

Forest plot of the length of postoperative hospital stay in patients with colorectal cancer and malignant intestinal obstruction undergoing endoscopic stent implantation followed by laparoscopic surgery and emergency surgery 

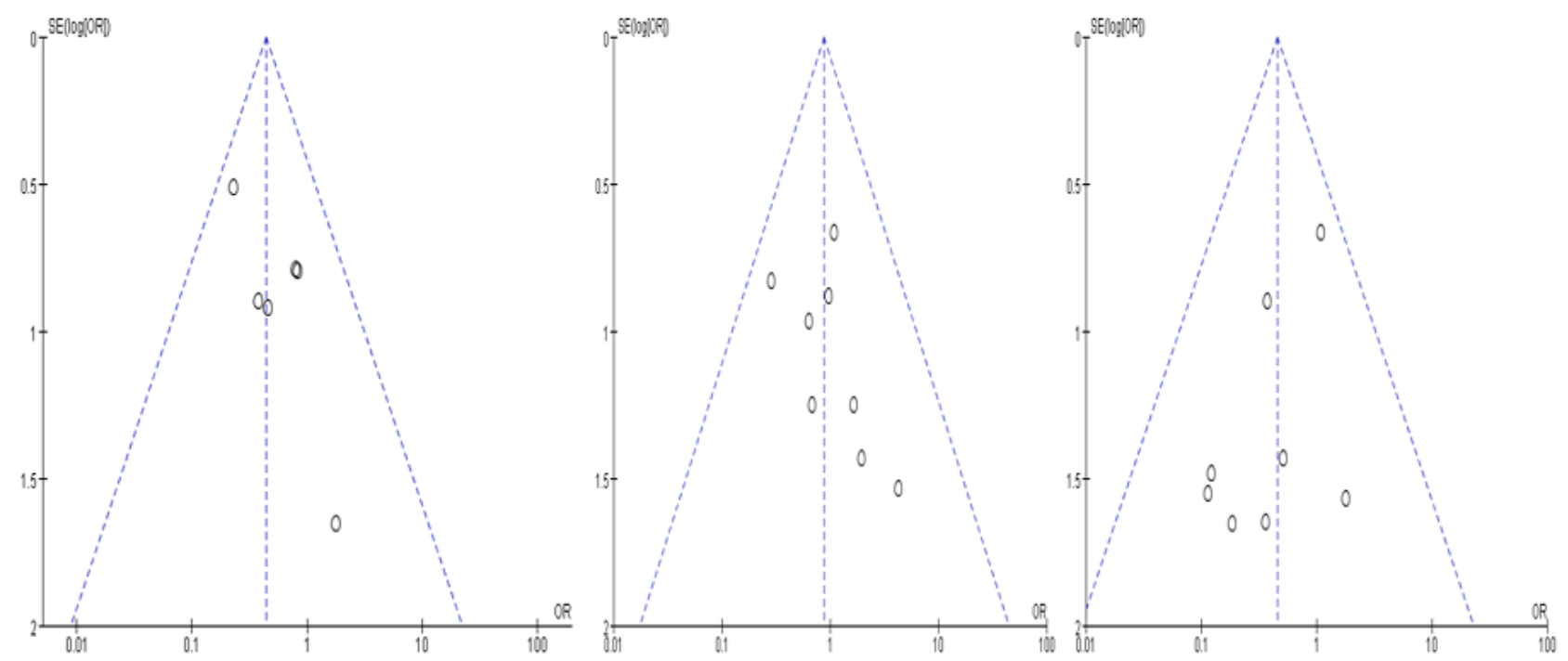

(a)

(b)

(c)

(a) Postoperative wound infection

(b) Anastomotic fistula (c) Perioperative mortality
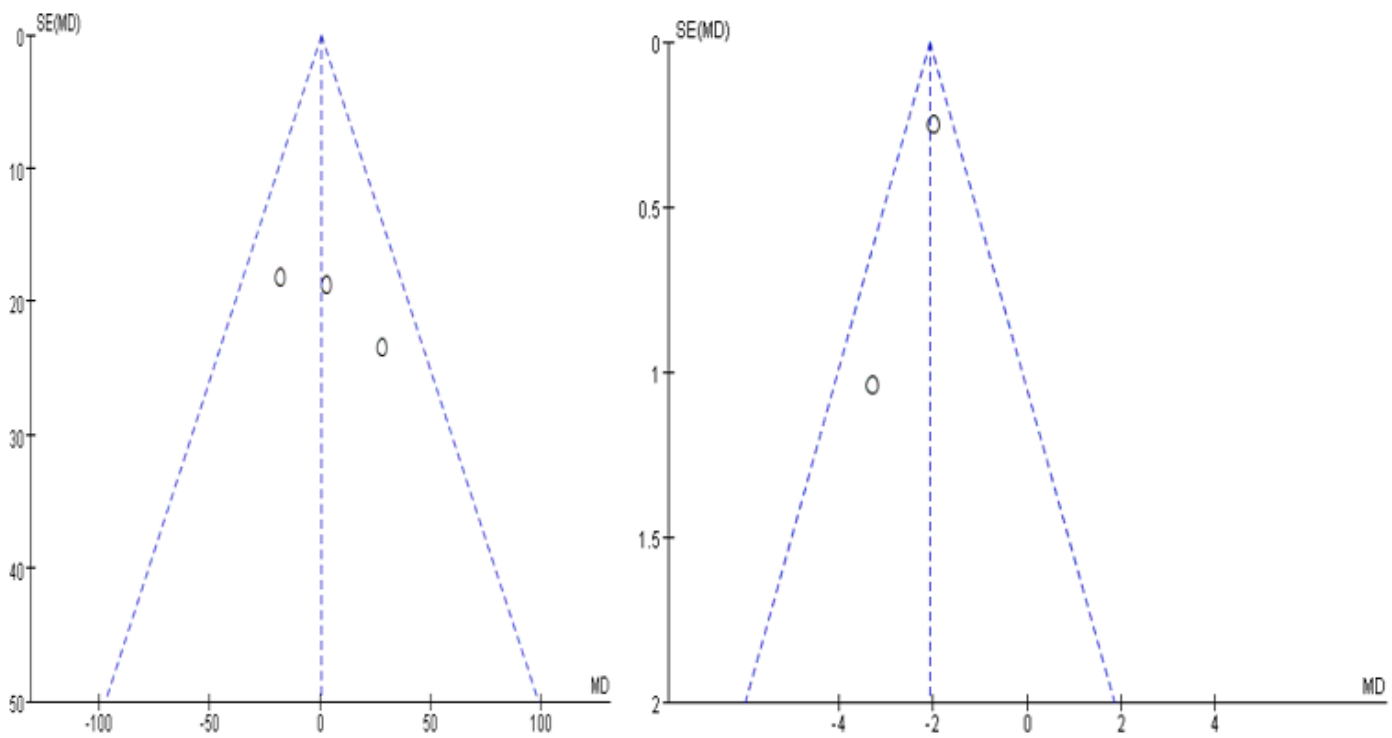

(d) operating time

(e) Length of postoperative hospital stay

Figure 7

Results of the funnel chart analysis of the five study criteria 